\title{
A Novel Application of Cellulose Aerogel Composites From Pineapple Leaf Fibers And Cotton Waste: Removal of Dyes and Oil In Wastewater
}

Phu V. Vu

Ho Chi Minh City University of Technology (HCMUT)

Trung D. Doan

Ho Chi Minh City University of Technology (HCMUT)

Giang C. Tu

Ho Chi Minh City University of Technology (HCMUT)

Nga H.N. Do

Ho Chi Minh City University of Technology (HCMUT)

Kien A. Le

Institute for Tropicalization and Environment

Phung K. Le ( $\nabla$ phungle@hcmut.edu.vn )

Ho Chi Minh City University of Technology (HCMUT) https://orcid.org/0000-0003-0570-3154

\section{Research Article}

Keywords: Pineapple Leaf Fibers, Cotton Waste, Aerogel Composite, Dye Removal, Oil Adsorption, Mechanical Strength.

Posted Date: December 1st, 2021

DOI: https://doi.org/10.21203/rs.3.rs-1102952/v1

License: (9) This work is licensed under a Creative Commons Attribution 4.0 International License.

Read Full License

Version of Record: A version of this preprint was published at Journal of Porous Materials on March 29th, 2022. See the published version at https://doi.org/10.1007/s10934-022-01238-w. 


\section{A Novel Application of Cellulose Aerogel Composites from Pineapple Leaf Fibers and Cotton Waste: Removal of Dyes and Oil in Wastewater}

Phu V. Vu' ${ }^{1,2}$, Trung D. Doan ${ }^{1,2}$, Giang C. Tu ${ }^{1,2}$, Nga H.N. Do ${ }^{1,2}$, Kien A. Le ${ }^{3}$, Phung K. Le ${ }^{1,2^{*}}$ ${ }^{1}$ Refinery and Petrochemical Technology Research Centre, Ho Chi Minh City University of Technology (HCMUT), 268 Ly Thuong Kiet Street, District 10, Ho Chi Minh City, Vietnam ${ }^{2}$ Vietnam National University Ho Chi Minh City, Linh Trung Ward, Thu Duc District, Ho Chi Minh City, Vietnam

3/nstitute for Tropicalization and Environment, 57A Truong Quoc Dung Street, Phu Nhuan District, Ho Chi Minh City, Vietnam

${ }^{*}$ Corresponding author:

Phung K. Le, Associate Professor, Faculty of Chemical Engineering, Ho Chi Minh City University of Technology (HCMUT), Ho Chi Minh City, Vietnam. Email: phungle@hcmut.edu.vn

\section{Abstract}

In a world where demands for freshwater are ever-growing, wastewater remediation becomes a global concern. Especially, water, which is contaminated by oil, dyes, poses challenges to the management of water resources. The development of innovative processes for wastewater treatment is still a major obstacle. With regard to its fast removal rate and environmental compatibility, cellulose aerogel composites are recently considered as a potential contributor for water remediation. In this study, cellulose aerogel composites are fabricated using the sol-gel method from two-agroindustrial wastes: pineapple leaf fibers and cotton waste fibers in alkali-urea solution followed by freeze-drying. The prepared cellulose aerogel composites are extremely lightweight with a low density $\left(0.053-0.069 \mathrm{~g} \mathrm{~cm}^{-3}\right)$ and high porosity of nearly $95 \%$. It is worth noting that the mechanical strength of the cellulose aerogel composites is remarkably improved with their Young's modulus increasing by 5-9 times compared to that of the previous aerogel composites using polyvinyl alcohol as a binder. The as-synthesized aerogel composites are directly applied to adsorb cationic methylene blue and exhibit a maximum adsorption uptake of $34.01 \mathrm{~g}^{-\mathrm{g}^{-1}}$. The methyltrimethoxysilane-coated cellulose aerogel composites also show their ability to deal with oil pollution with a maximum oil adsorption capacity of $15.8 \mathrm{~g} \cdot \mathrm{g}^{-1}$ within only 20 sec. Besides the oil removal, our developed cellulose aerogel composites have demonstrated their capability in treating dye-contaminated wastewater for the first time based on their evidenced ability to eliminate methylene blue.

Keywords: Pineapple Leaf Fibers, Cotton Waste, Aerogel Composite, Dye Removal, Oil Adsorption, Mechanical Strength. 


\section{Introduction}

Environmental pollution, particularly water pollution, is currently a major global issue imposing a serious threat to both human and ecosystem health. According to statistics, water pollution is responsible for roughly 14.000 fatalities each day [1]. Amongst various pollution causes, organic pollutants comprising soluble dyes and insoluble oils are the main contaminants in wastewater [1,2]. The amount of these pollutants have been significantly increasing due to an increase in industrial activities and oil spill incidents [3].

Oily wastewater devastates both aquatic and terrestrial lifeforms in the marine areas and has even detrimental economic impacts on tourism and fishing. Interaction with spilled oils has not only killed innumerable aquatic organisms (such as sea birds, mammals, algae, and so on) but the sand on seashore beaches has also been badly polluted [4,5]. Deepwater Horizon, the biggest oil spill in U.S. history, released an estimated 4.9 million barrels of oil into the ocean resulting in severe damage to marine life, coastal wetlands, the fishing industry, tourism, and so on [4-6]. Additionally, the toxic effects of dye-contaminated water relate to the risk of dyes degrading into carcinogenic amine substances whilst the dark hue of certain dyes interferes with the photosynthetic activity of marine plants [7]. Therefore, an effective technique for the removal of dyes and oils from wastewater is urgently required.

Despite many attempts in treatment of the contaminated wastewater, adsorption has plenty of advantages such as high efficiency, cost-effectiveness, and ease of use for dye and oil remediation [2]. However, conventional adsorbents such as inorganic absorbents, natural fibers, and synthetic organic polymers have several detrimental aspects involving secondary pollution, poor selectivity, and limited sorption capacity [8]. Consequently, studies to eliminate the limitations of previous adsorbents and develop a novel material with superior properties should be urgently performed. Furthermore, the process of synthesizing adsorbents should be improved to meet the criteria of green chemistry and avoid the release of waste into the environment.

Cellulose-based aerogels owning outstanding features such as low density, high porosity, large specific surface area, and excellent flexibility have attracted worldwide attention over the past decade [5]. Various studies have revealed that it could be an excellent material to remove oil and dye effectively in contaminated water $[6,9,10]$. The sources to produce cellulose aerogels are diverse, but cellulose-originated wastes, especially biomass and textile waste, are of primary interest since they are appropriate for developing eco-friendly production technologies with the use of renewable feedstocks [11]. Aerogels prepared from cellulose-rich waste are biodegradable, easy to be functionalized for different uses, and inexpensive due to the abundance of raw materials [5]. Do et al. developed cellulose 
aerogels from pineapple agricultural waste that had excellent properties for applications such as sound insulation, thermal insulation, as well as oil and organic solvent adsorption $[12,13]$. Later generations of cellulose aerogel have been developed with the addition of reinforcements, for example, polymers, metals, and inorganic compounds to obtain novel aerogel composites that not only keep aerogel-like properties but also have improved compressive strength, elasticity, toughness, and high module-to-volume ratio $[14,15]$. Cheng et al. fabricated cotton aerogels and cotton-cellulose aerogels using recycled fibers for oil-spill cleaning up [16]. The adsorption capacity for various oils and organic solvents could range from 19.8 to 41.5 grams per gram of cotton fiber-derived aerogel fabricated by Wang and Liu [17]. Lim et al. synthesized pineapple aerogels functionalized with activated carbon and diethylenetriamine for respective ethylene adsorption in fruit preservation and removal of nickel ions in water treatment. The modified aerogels exhibit significant adsorption uptake of 1.08 and $0.835 \mathrm{mmol} / \mathrm{g}$ for ethylene and nickel ion adsorption, respectively [18]. Do et al. invented heat-insulating aerogel composites by the consolidation of pineapple leaf fibers (PFs) and discarded cotton fibers (CFs) and the use of polyvinyl alcohol as a cross-linker. The obtained aerogel composite showed an increase in their compressive modulus from 11.33 to $44.63 \mathrm{kPa}$ with increasing the total fiber content [15]. A simple alkali-urea method without consumption of any crosslinkers was developed by Fauziyah et al. in the synthesis of cellulose aerogels from coir fibers. Briefly, a mixture of sodium hydroxide $(\mathrm{NaOH})$ and urea at a fixed concentration is applied to cause cellulose fibers to swell and disperse uniformly without agglomeration, followed by sol-gel with absolute ethanol at room temperature and freeze-drying $[19,20]$.

To the best of our knowledge, there has been no study on the fabrication of pineapple aerogels via the advanced alkali-urea method as well as their application of dye removal in wastewater. In this work, novel cellulose aerogel composites from a combination of PFs and CFs are synthesized via $\mathrm{NaOH} /$ urea method with a modification of using $60{ }^{\circ} \mathrm{C}$ absolute ethanol to promote gelation faster and shorten the synthesis time. The obtained PF/CF aerogel composites are characterized in terms of their density, porosity, surface morphology, mechanical properties, and thermal stability. The PF/CF aerogel composites are also evaluated for their capability to remove aqueous methylene blue which is a chemical extensively used in the disciplines of biology and medicine, as well as in the textile industry, coloring fabric, silk, and cotton [21]. Because the molecular size of MB is approximately 1.38 $\mathrm{nm}$ [22] smaller than the pore size of the analyzed sample points so it is appropriate for this investigation. Besides, the adsorption of engine oil for oil absorption application was also investigated. The effect of total fiber content on some characteristics such as physical- 
mechanical properties, maximum adsorption capacity, adsorption kinetics, adsorption isotherms, and thermodynamics of the aerogel composite is comprehensively studied.

\section{Materials and methods}

\subsection{Materials}

PFs with a cellulose content of $75.2 \%$ were purchased from Conifer Handmades Company, India. Tensile strength and Young's modulus of PFs are respectively 29.8 and $981 \mathrm{MPa}$ according to the supplier. CFs gathered from local textile companies after carding have a high cellulose content ( $85 \%$ ), a length of $21.78 \mathrm{~mm}$, a maximum ash level of $1.8 \%$, insoluble matter content of $4.0-6.0 \%$, the moisture of $8.0 \%$, and specific strength of $23 \mathrm{g.tex}^{-1}$. Commercial 5w30 motor oil (ExxonMobil Corporation, USA) was bought from local market. Sodium hydroxide $(\mathrm{NaOH})$, ethanol, urea, methylene blue $(\mathrm{MB})$ were purchased from Xilong Scientific Co., Ltd, China. Methyltrimethoxysilane (MTMS, 97\%) from Alfa Aesar. All solutions were prepared in distilled water (DW).

\subsection{Aerogel composites synthesis}

$\mathrm{NaOH} /$ urea/water solution was firstly prepared in a mass ratio of 7:12:81 at room temperature. PFs were milled to a fine powder (ca. $100 \mu \mathrm{m}$ ) before being mixed CFs in a different solid mass proportion of $1: 2,2: 1$, and 4:1, respectively. Each mixture of PFs and CFs was then dispersed into the $\mathrm{NaOH} /$ urea/water solution, refrigerated to $0{ }^{\circ} \mathrm{C}$ for 15 minutes, and magnetically stirred to achieve a homogeneous dispersion containing the total fiber content of $4 \mathrm{wt} \%$. The system was frozen for 24 hours and then defrosted to create strong hydrogen bonding between the fibers. The suspension was poured into a cylinder mold and incubated with $60{ }^{\circ} \mathrm{C}$ ethanol to promote gelation before being washed with DW to remove excessive $\mathrm{NaOH}$ and urea. Finally, the whole mixture was frozen at $-50{ }^{\circ} \mathrm{C}$ for 4 hours and freeze-dried for roughly 50 hours to yield PF/CF aerogel composites. The hydrophobic aerogel composites were obtained via a simple chemical vapour deposition with MTMS as described in our previous study [12].

\subsection{Characterization of cellulose aerogel composite}

The bulk density of each aerogel composite is determined via its weight and volume. Its porosity $(\varphi)$ is calculated based on its bulk density $\left(\rho_{a}\right)$ and the average density of components $\left(\rho_{b}\right)$ as indicated by Eq. (1) [15]:

$$
\varphi=\left(1-\frac{\rho_{a}}{\rho_{b}}\right) \times 100 \%
$$


where $\rho_{b}$ is determined by using Eq. (2):

$$
\rho_{b}=\frac{C_{P F} \times \rho_{P F}+C_{C F} \times \rho_{C F}}{C_{P F}+C_{C F}}
$$

where $\rho_{P F}=1.07 \mathrm{~g} . \mathrm{cm}^{-3}$ and $\rho_{C F}=1.56 \mathrm{~g} . \mathrm{cm}^{-3}$ are the density of PF and CF, respectively. $C_{P F}$ and $C_{C F}$ are the mass concentration of PF and CF, respectively.

Field-Emission Scanning Electron Microscope (FE-SEM Hitachi S4800) is applied to investigate the porous structure of samples at an acceleration voltage of $10 \mathrm{kV}$ [23]. All samples are coated with a thin layer of Pt for 30 seconds before measurement [24].

Fourier Transform Infrared spectrometer (FTIR) PerkinElmer FTIR device (USA) is used to analyze the chemical structure of the PF/CF aerogel composites with and without coating with MTMS. The samples are characterized in the wide range of wavenumber from 4000 to $550 \mathrm{~cm}^{-1}$ at a resolution of $4 \mathrm{~cm}^{-1}$ using the attenuated total reflection testing.

Thermogravimetric analysis (TGA) curves are recorded by a TGA analyzer (LINSEIS DSC PT 1600). All surveyed samples are heated from $40{ }^{\circ} \mathrm{C}$ to $800{ }^{\circ} \mathrm{C}$ at a heating rate of 10 ${ }^{\circ} \mathrm{C} . \min ^{-1}$.

Ultraviolet-visible (UV-VIS) spectrometer Shimadzu's UV-1800 is utilized to analyze the absorption of light intensity of incoming beam through sample solution placed in a cuvette. The wavelength of the incoming beam is $640 \mathrm{~nm}$ corresponding to the color wavelength of MB.

The compressive property of PF/CF aerogel composites samples is evaluated by using an Instron 5500 Universal Testing Machine with a compression rate of $10 \mathrm{~mm} \cdot \mathrm{min}^{-1}$. The obtained data are plotted as a curve of stress and strain. The Young's modulus of each aerogel composite is determined from the fit linear at less than $10 \%$ strain.

\subsection{Study on oil removal of hydrophobic PF/CF aerogel composites}

In this study, 5w30 motor oil is used for evaluating oil removal of the aerogel composites. The initial mass $m_{0}$ of the sample is firstly weighed by a 4-digit analytical balance. The sample is then placed in the beaker containing 5w30 motor oil for more than $1 \mathrm{~min}$. The material sample is submerged in a beaker of 5w30 motor oil for 1 hour to guarantee that the most oil could penetrate the pore structure of the sample to evaluate the maximum adsorption. Finally, the sample is placed on a sieve, allowed to drain for 2 minutes, and then the adsorbed mass is reweighed. The experiment is repeated three times to determine the average value, which is the maximum oil adsorption capacity of the aerogel composite. 
Oil adsorption capacity $q_{t}$ is measured at $5,10,15,20,30,40,50$ (seconds) to identify the most suitable adsorption kinetic model for the aerogel composite.

The adsorption capacity of each sample at the time $t$ is calculated using the following Eq. (3):

$$
q_{t}=\frac{m_{t}}{m_{o}}
$$

Where $m_{t}(\mathrm{~g})$ is the composite weight at the time $\mathrm{t}$, and $m_{o}(\mathrm{~g})$ is the composite weight at the initial time.

In the adsorption mechanism, kinetic prediction of the adsorption capacity and adsorption time play an important role. Kinetic data are analyzed using pseudo-first order and pseudo-second order models to characterize the dependency of the oil adsorption on time. The pseudo-first order model can be expressed as Eq. (4) [25]:

$$
\ln \frac{q_{e}}{\left(q_{e}-q_{t}\right)}=k_{1} \cdot t
$$

Where $q_{e}$ and $q_{t}\left(\mathrm{~g} \mathrm{~g}^{-1}\right)$ are the amounts of $5 \mathrm{w} 30$ oil $\left(\mathrm{g} \cdot \mathrm{g}^{-1}\right)$ adsorbed on adsorbent at equilibrium and various time $t(\mathrm{sec})$, respectively. $k_{1}\left(\mathrm{sec}^{-1}\right)$ is the kinetic rate constant of the pseudo-first order model of adsorption.

The pseudo-second order model is another kinetic model that includes several types of adsorptions such as external film diffusion, adsorption, and internal particle diffusion ts equation can be given as Eq. (5) [25]:

$$
\frac{t}{q_{t}}=\frac{1}{k_{2} \cdot q_{e}^{2}}+\frac{t}{q_{e}}
$$

Where $q_{e}$ and $q_{t}\left(\mathrm{~g} \mathrm{~g}^{-1}\right)$ are the amounts of $5 \mathrm{w} 30$ oil $\left(\mathrm{g} \cdot \mathrm{g}^{-1}\right)$ adsorbed on adsorbent at equilibrium and various time $t(\mathrm{sec}) . k_{2}\left(\mathrm{~g} \cdot \mathrm{g}^{-1} \cdot \mathrm{sec}^{-1}\right)$ represents the rate constant of the pseudo-second order model of adsorption.

\subsection{Study on cationic dye removal of PF/CF aerogel composites}

To process the experiment, $0.1 \mathrm{~g}$ of solid MB is dissolved in distilled water in a $1000 \mathrm{~mL}$ cylinder to create a 1000 ppm MB standard sample solution. The standard sample is diluted into MB solutions with concentrations of 25, 50, 75, 100, 125 (ppm) for kinetic and isothermal adsorption studies, respectively.

PF/CF Aerogel composites with different proportions of fibers (PC41, PC21, PC11) are weighed to $0.05 \mathrm{~g}$, placed in $25 \mathrm{~mL}$ of $\mathrm{MB}$ color solution at room temperature, and shaken well under time conditions. After adsorption, the sample is removed, and UV-VIS analyzes 
the MB color solution adsorption at $640 \mathrm{~nm}$; the result obtained is the solution's absorbance. Each composition is performed three times to determine the average value and standard deviation.

The adsorption capacity at the time $\left(q_{t}, \mathrm{mg} \cdot \mathrm{g}^{-1}\right)$ is calculated by the Eq. (6):

$$
q_{t}=\frac{\left(C_{o}-C_{t}\right) \cdot V}{m}
$$

Where $C_{o}, C_{t}(\mathrm{ppm})$ are the concentrations of $\mathrm{MB}$ in the initial solution and at the $\mathrm{t}$ time, respectively; $V(\mathrm{~L})$ is the volume of solution, and $m(\mathrm{~g})$ is the initial aerogel composite mass. To conduct a kinetic adsorption experiment, the investigation time for the experiment is 15 , $20,25,30,45,60$, and 75 ( $\mathrm{min}$ ) with MB color solution with the initial concentration of 50 ppm. The adsorption parameters of the research experiment according to the first and second-order apparent kinetic models of adsorption is the same as those of the oil adsorption experiment. Experiment for isothermal studies with MB color solution starting concentrations of $25,50,75,100$, and 125 (ppm).

Finally, the removal efficiency of $\mathrm{MB}(\mathrm{H} \%)$ refer to the total amount of adsorbed with respect to the total initial concentration of adsorbent is calculated according to Eq. (7):

$$
H \%=\left(\frac{C_{0}-C_{e}}{C_{0}}\right) .100
$$

Where $\mathrm{C}_{0}$ and $\mathrm{C}_{\mathrm{e}}$ refer to the initial and equilibrium concentration of $\mathrm{MB}$ (ppm), respectively. The kinetics study of MB adsorption is done by using the pseudo-first order model and pseudo-second order model followed by Eq. (4) and Eq. (5), as mentioned above.

The Langmuir isotherm model is suitable for the monolayer adsorption occurring on a homogeneous surface without subsequent interaction among the adsorbed species. The model can be expressed as Eq. (8) [25]:

$$
\frac{C_{e}}{q_{e}}=\frac{C_{e}}{q_{m}}+\frac{1}{q_{m} \cdot K_{L}}
$$

Where $K_{L}\left(\mathrm{~L} . \mathrm{mg}^{-1}\right)$ is the Langmuir constant. $q_{e}, q_{m}\left(\mathrm{mg} \cdot \mathrm{g}^{-1}\right)$ is the equilibrium adsorption and the maximum adsorption capacity of adsorbate, respectively. $C_{e}(\mathrm{ppm})$ is the equilibrium concentration of the adsorbate.

The constant $K_{L}$ characterizes the interaction force between the adsorbent and the adsorbate at a certain temperature, or in other words, $K_{L}$ describes the adsorption center's 
selectivity. Construct a graph $C_{e} / q_{e}$ based on $C_{e}$ to determine the adsorption constants $K_{L}$ and $R^{2}$ as well as the maximum adsorption $q_{m}$. From the $K_{L}$ value, it is possible to assess whether the adsorption process is suitable or not in the investigated concentration range of the adsorbent through the equilibrium parameter $R_{L}$ determined as Eq. (9) [26]:

$$
R_{L}=\frac{1}{1+K_{L} \cdot C_{o}}
$$

Where $R_{L}$ is the equilibrium parameter, $K_{L}$ is the Langmuir constant, and $C_{o}(\mathrm{ppm})$ is the initial concentration of the adsorbate

The Freundlich isotherm model can be described as Eq. (10) [27]:

$$
\ln q_{e}=\ln K_{F}+\frac{\ln C_{e}}{n}
$$

Where $K_{F}$ is the Freundlich adsorption constant, and $n$ is the empirical constant, indicating the quantity that evaluates the degree of heterogeneity of the adsorbent surface and describing the appropriateness of adsorbent molecule distribution on the surface of the adsorbent. A value of $n$ higher than 1 implies that molecules are adsorbing well onto the adsorbent surface. The higher the value $n$, the higher the adsorption strength. Construct a graph of $I n q_{e}$ dependent on $I n C_{e}$, thereby determining $R^{2}$, the Freundlich constant $K_{F}$ and the empirical constant $n$.

Standard free energy or Gibbs free energy $\Delta G^{\circ}$ is a standard to evaluate whether a process is spontaneous or not. When $\Delta G^{\circ}$ is negative at a given temperature, the process will proceed spontaneously and is referred to as exergonic. Changes in the thermodynamic partition coefficient with temperature changes. The standard free energy can be determined by the thermodynamic equilibrium constant $K^{\circ}$ (or thermodynamic distribution coefficient), $K^{\circ}$ calculated by Eq. (11) [28]:

$$
K^{\circ}=\frac{\gamma_{s} \cdot C_{s}}{\gamma_{e} \cdot C_{e}}
$$

Where $\gamma_{s}$ is the activity coefficient of adsorbed ions, $\gamma_{e}$ is the activity coefficient at equilibrium, $C_{s}$ is the concentration of adsorbate on the adsorbent, and $C_{e}$ is the concentration of adsorbate at equilibrium time

The $K^{\circ}$ expression can be simplified by assuming that the concentration in the solution approaches zero resulting $C_{s}$ in $\rightarrow 0$ and $C_{e} \rightarrow 0$, and the activity coefficients approach unity at these very low concentrations. It can be written as Eq. (12): 


$$
K^{\circ}=\frac{C_{s}}{C_{e}}
$$

The Gibbs free energy is calculated using the following Eq. (13):

$$
\Delta G^{\circ}=-R \cdot T \cdot \ln K^{\circ}
$$

Where $R\left(8.314 \mathrm{~J} \mathrm{~mol}^{-1} \cdot \mathrm{K}^{-1}\right)$ is the ideal gas constant, and $T(\mathrm{~K})$ is absolute temperature [29].

\section{Results and discussions}

\subsection{Characterization of PF/CF aerogel composite}

Lyophilization is the preferred technique in the synthesis of aerogel composites from PF and CF in order to avoid structural damage. As the result, the porous structure of developed aerogel composites with high porosity is clearly observed through SEM images in Fig. 1. The pores inside the structure of aerogel composites created by PFs (straight, sizes 40-60 $\mu \mathrm{m}$ ) and CFs (twisted, sizes 10-20 $\mu \mathrm{m}$ ) were primarily macropores, ranging from 30 to 90 $\mu \mathrm{m}$. Furthermore, the increase of CF concentration causes a more packed structure, resulting in a remarkable decrease in the diameter of the pores [16]. The results are consistent with previous studies on PF/CF aerogel composites [15]. At the same time, the arrangement and linkage between the fibers are disordered as they are cast on the mold randomly before adding the $\mathrm{NaOH} / \mathrm{urea} /$ water solution, which make the cellulose chains swelling and dissolving into solution, then gelation caused by physical cross-linking of cellulose chains to form the structure of the material [30].

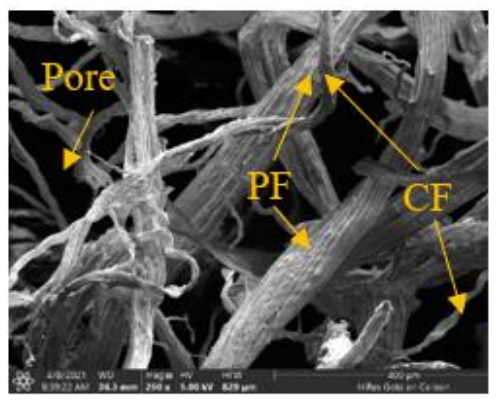

(a)

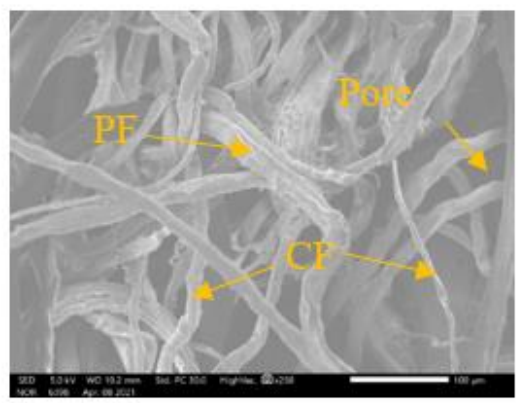

(b)

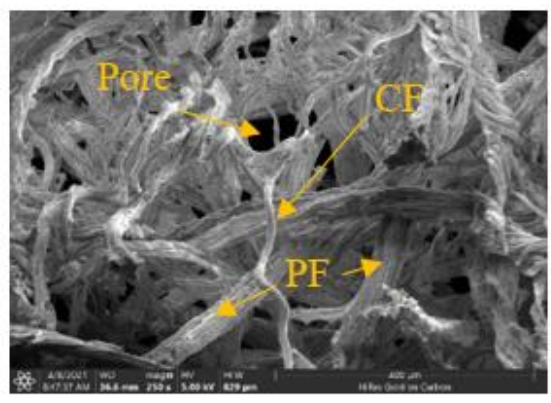

(c)

Fig. 1 SEM images of PF/CF aerogel composites with vary PF/CF ratio (a) 4:1; (b) $2: 1$; (c) $1: 1$

The physical properties of the aerogel composite samples in terms of density and porosity were measured and are shown in Table 1. The results reveal that the obtained aerogel composites possess a low density in the range of $0.053-0.069 \mathrm{~g} . \mathrm{cm}^{-3}$ and high porosity of 94.7-95.2\%, indicating their highly porous structure after synthesis. Increasing the CF content whilst remaining the total fiber content unchanged (4\%) results in an increase in the 
density of the aerogel composite from 0.053 to $0.069 \mathrm{~g} . \mathrm{cm}^{-3}$. This can be explained by the fact that the density of CF $\left(1.56 \mathrm{~g} . \mathrm{cm}^{-3}\right)$ is greater than that of PF $\left(1.07 \mathrm{~g} . \mathrm{cm}^{-3}\right)$ [15]. Compared to the previous work, our PF/CF aerogel composite have a higher density and lower porosity than that of PF/CF aerogel composite synthesized by Do et al. (density of $0.019-0.046 \mathrm{~g} . \mathrm{cm}^{-3}$ and porosity $96.1-98.4 \%$ ) [15].

Table 1. Summary of density, porosity, and compressive strength of PF/CF aerogel composite

\begin{tabular}{ccccc}
\hline Sample & PF:CF $(\mathrm{g} / \mathrm{g})$ & Density $\left(\mathrm{g} . \mathrm{cm}^{-3}\right)$ & Porosity $(\%)$ & $\begin{array}{r}\text { Compressive } \\
\text { modulus }(\mathrm{kPa})\end{array}$ \\
\hline PC41 & $4: 1$ & $0.053 \pm 0.005$ & $95.2 \pm 0.46$ & 90.97 \\
PC21 & $2: 1$ & $0.061 \pm 0.002$ & $95.0 \pm 0.26$ & 145.28 \\
PC11 & $1: 1$ & $0.069 \pm 0.003$ & $94.7 \pm 0.24$ & 203.72 \\
\hline
\end{tabular}

The correlation between compressive stress and corresponding strain of the PF/CF aerogel composite with different mixing ratios of the two fiber compositions is shown in Fig. 2.a, and their Young's modulus parameter is tabulated in Table 1. From the results, it can be seen that the synthesized aerogel composites exhibit a high compressive modulus of $90.97 \mathrm{kPa}$ (PC41), $145.28 \mathrm{kPa}$ (PC21), and $203.72 \mathrm{kPa}$ (PC11). These parameters are approximately 5-9 times as much as those of PF/CF aerogel composite produced via the crosslinking method with PVA (11.33-44.63 kPa) [15] and are much higher than those of PF only aerogel (1.64-5.34 kPa) [13]. The higher compressive strength of the material can be explained by the fact that when the fibers are dispersed with $\mathrm{NaOH} / \mathrm{Urea} / \mathrm{H}_{2} \mathrm{O}$ aqueous solution and then gelation with ethanol, the cellulose fibers are bonded together by intramolecular and intermolecular hydrogen bonds which make the structure become tight aggregates than when using PVA as a cross-linking [30]. The stress-strain curves of aerogel composites show a linear line at strains less than 10\%; this linear elastic region shows the ability to fully recover to the original state before deformation. A smooth plastic yielding region witnessed at the compression strain of $10-60 \%$ demonstrates the collapse of the porous structure. Finally, a densification area is observed for compression strains greater than $60 \%$, where stress is dramatically increased. As in Fig. 2a, when CF content increases, the mechanical strength under the same pressure point is greater. This proves that CF plays a role in the reinforcement of the hollow structure of the PF/CF aerogel composite, and increasing CF content makes the fabricated composites stiffer 

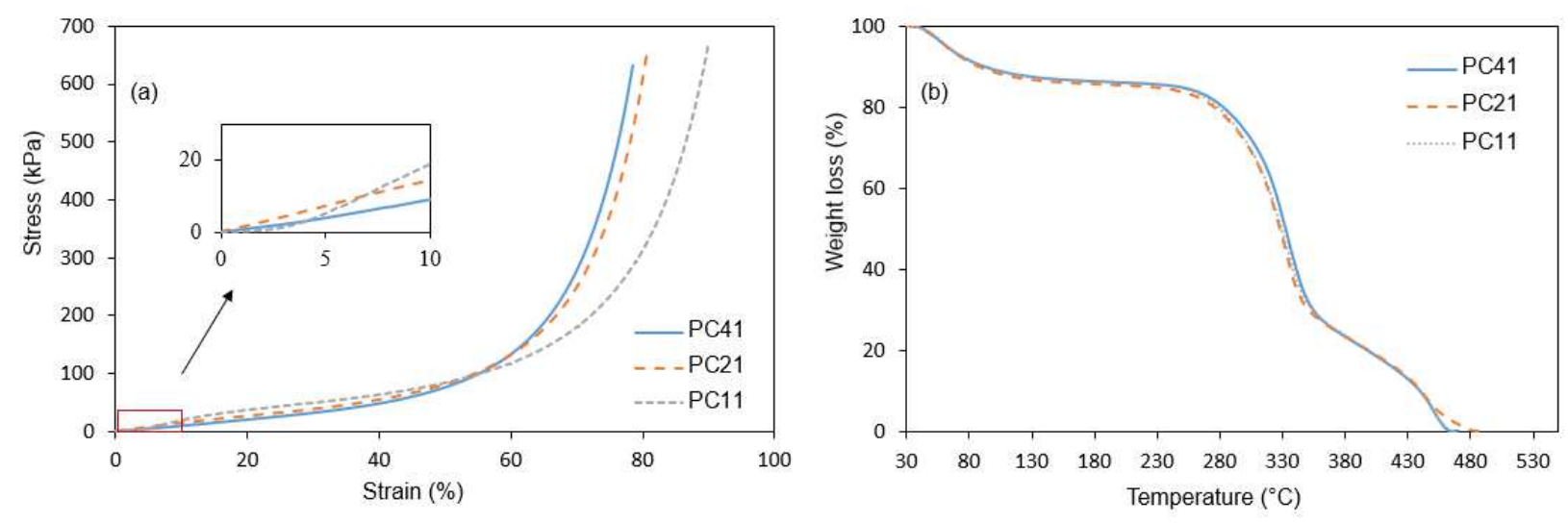

Fig. 2 Stress-strain (a) and TGA (b) curves of PF/CF aerogel composites with different fiber ratios.

The graph of TGA analysis of PF/CF aerogel composite is shown in Fig. 2.b. From the graph, it can be seen that changing the mixing PF/CF ratios has no significant effect on the mass loss of aerogel composites by thermal decomposition. The PF/CF aerogel composites exhibit a typical thermogram with mass degradation in three phases by the temperature as follows: (i) $60-100{ }^{\circ} \mathrm{C}$, (ii) $270-350{ }^{\circ} \mathrm{C}$, and (iii) $360-460{ }^{\circ} \mathrm{C}$. At the first step, the sample weight decreased from 8 to $10 \%$, attributed to the evaporation of moisture. The reason for this phenomenon is because the PF/CF aerogel composites after drying still have a small amount of moisture inside and contain many hydroxyl groups on cellulose chains of two types of constituent fibers that absorb water in the air. At the next stage from 270 to $350{ }^{\circ} \mathrm{C}$, a drastic decline of about $67-70 \%$ is witnessed in the mass of all composite samples caused by oxidative decomposition of organic compounds including cellulose, hemicellulose, lignin [13]. Eventually, the mass degradation of aerogel composites occurs rapidly from $360{ }^{\circ} \mathrm{C}$ until the material is completely decomposed at $460^{\circ} \mathrm{C}$, and the rest is ash. As a result, the highest stable temperature range for PF/CF aerogel composites is around $230-280{ }^{\circ} \mathrm{C}$, compared with PF/CF aerogel composite synthesized by Do et al., there is no significant difference in stable temparature range as they come from the same material.

\subsection{Oil adsorption of the PF/CF Aerogel Composites}

The PF/CF aerogel composites after MTMS coating is hydrophobic because the $-\mathrm{OH}$ groups of cellulose are displaced by - O-Si- $\left(\mathrm{CH}_{3}\right)_{3}$ groups from MTMS, indicating by not absorbing water droplets on the surface as shown in Fig. 3.a. The maximum oil adsorption of the material is $15.8 \mathrm{~g} . \mathrm{g}^{-1}$ with sample PC41, and the lowest adsorption is $11.3 \mathrm{~g}^{-\mathrm{g}^{-1}}$ with sample PC11 (Fig. 3.b). This shows that the higher the porosity, the better the adsorption capacity. The aerogel composites have higher oil adsorption when compared with coir- 
based aerogels prepared by the same alkali-urea method $\left(\begin{array}{llll}10 & \mathrm{~g} \cdot \mathrm{g}^{-1}\end{array}\right)$ [31].
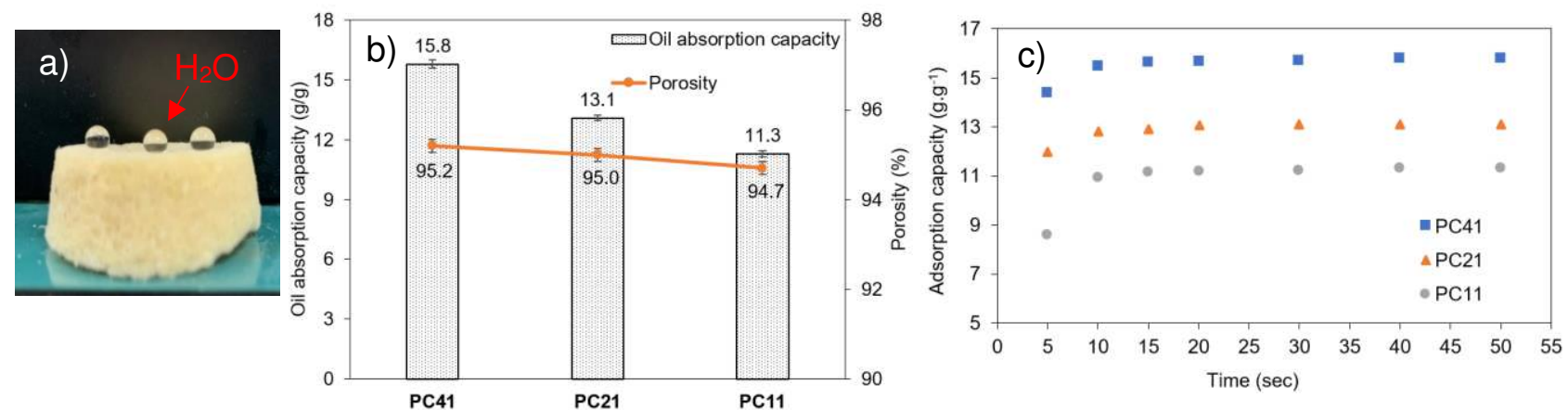

Fig. 3 (a) PF/CF aerogel composite coated MTMS does not absorb water droplets (b) 5 w30 oil adsorption of PF/CF aerogel composite (c) Oil adsorption kinetics of PF/CF aerogel composite with different ratios

Oil adsorption capacity gradually increase with the adsorption time of PF/CF aerogel composite (Fig. 3.c). The material exhibits oil adsorption fastest in the first 10 seconds then reaches equilibrium after about 20 seconds. PF/CF aerogel composite can quickly adsorb oil because of its porous structure and 3D space structure. Besides, oil can enter the structure of material through hydrophobic interaction, capillary force [18,32] (Fig. 4).
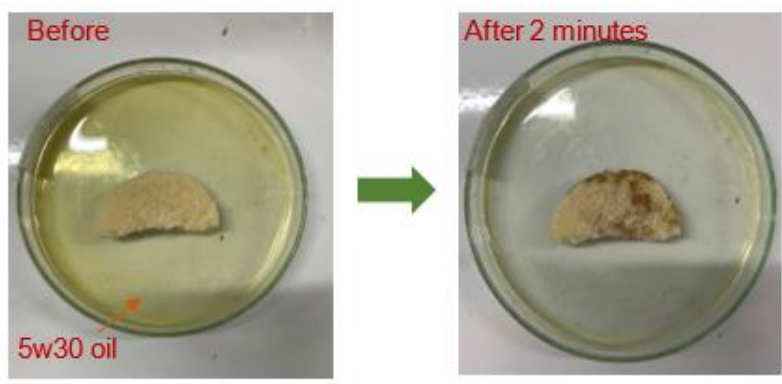

Fig. 44 PF/CF aerogel composite 5w30 oil removal

The $R^{2}$ values for both models are calculated and shown in Table 2. As a result, the $5 \mathrm{w} 30$ motor oil adsorption process of PF/CF aerogel is consistent with the pseudo-second order model with $\mathrm{R}^{2}$ values closer to 1 than the pseudo-first order model, which indicate the adsorption is fast in the beginning and then slows down towards equilibrium.

Table 2. Kinetics parameters for the oil adsorption of PF/CF aerogel composite

\begin{tabular}{ccccc}
\hline Samples & & PC41 & PC21 & PC11 \\
\hline Pseudo-first order & $\mathrm{k}_{1}$ & 0.192 & 0.182 & 0.138 \\
Pseudo-second order & $\mathrm{R}^{2}$ & 0.879 & 0.852 & 0.918 \\
& $\mathrm{k}_{2}$ & 0.164 & 0.204 & 0.090 \\
& $\mathrm{R}^{2}$ & 0.999 & 0.999 & 0.999 \\
\hline
\end{tabular}




\subsection{Dye removal of PF/CF aerogel composites}

\subsubsection{Adsorption kinetic}
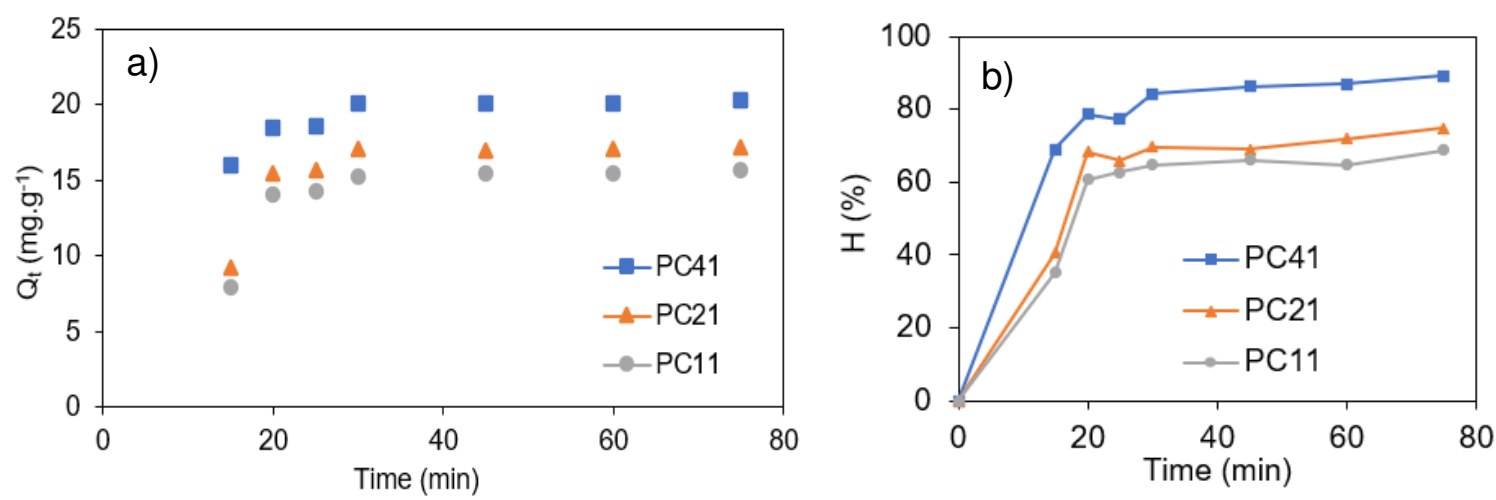

Fig. 5 (a) MB adsorption kinetics of PF/CF aerogel composite with different ratios (b) Effect of contact time on MB absorption by PF/CF aerogel composite

It can be seen from Fig. 6 that all three materials with different fiber ratios have a fast adsorption time in the first 20 min due to the diffusion process to the large surface without obstruction, as well as the number of empty adsorption centers. At the same time, it can be observed that the lower the porosity of the material, the lower the adsorption capacity. Adsorption equilibrium was reached about $30 \mathrm{~min}$ from when the material was placed in the MB solution. The explanation for the short-time adsorption is because (1) the material has a porous structure and high surface area, (2) there is a hydrogen interaction between the hydroxide functional group ( $-\mathrm{OH}$ ) of cellulose and nitrogen atoms on MB [33], (3) capillary force bring MB from the surface to the interior of the material. It can be concluded that the adsorption undergoes rapid adsorption stages on the surface of the material, so the adsorption increases the first time very quickly. The diffusion process into the porous structure inside the material and this process continue until equilibrium is reached. Both common model pseudo-first-order and pseudo-second-order are also studied. The $\mathrm{R}^{2}$ values for both models are calculated and shown in Table 3. Since the MB adsorption process of PF/CF aerogel follows the pseudo-second-order model with $\mathrm{R}^{2}$ values closer to 1 than the pseudo-first-order model.

Table 3. Kinetics parameters for the MB adsorption of PF/CF aerogel composite

\begin{tabular}{ccccc}
\hline Samples & & PC41 & PC21 & PC11 \\
\hline \multirow{2}{*}{ Pseudo-first order } & $\mathrm{k}_{1}$ & -0.0637 & -0.0692 & -0.0813 \\
& $\mathrm{R}^{2}$ & 0.647 & 0.723 & 0.680 \\
Pseudo-second order & $\mathrm{k}_{2}$ & 0.0134 & 0.0064 & 0.0057 \\
& $\mathrm{R}^{2}$ & 0.998 & 0.966 & 0.955 \\
\hline
\end{tabular}




\subsubsection{Adsorption isotherms}
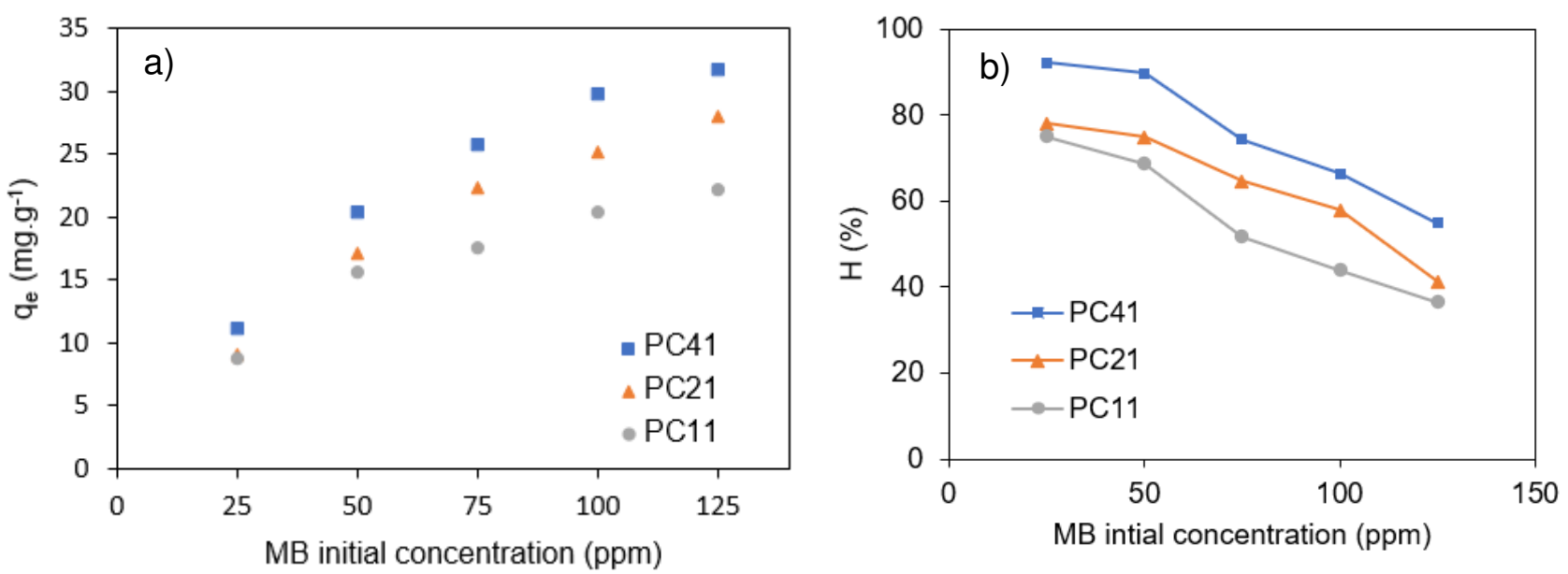

Fig. 6 (a) Adsorption isothermal of PF/CF aerogel composite (b) Effect of initial concentration of MB on MB absorption by PF/CF aerogel composite

Fig. 7 shows that the adsorption capacity increases with increasing initial MB concentration. With a fixed amount of material, there is a constant number of adsorption centers. Therefore, when the concentration of MB is increased to a certain level, a saturated adsorption state will be reached which followed by the drop of removal efficiency on MB absorption. Two models isotherms of PF/CF aerogel composite are investigated (Fig. 8), the adsorption data according to Langmuir and Freundlich adsorption isotherm models (Table 4) gives results that fitted Langmuir's model with higher $\mathrm{R}^{2}$, which indicates that the adsorption process is monolayer on the surface of the material. The $R\llcorner$ values are all in the range between 0 and 1, representing the suitable initial concentrations chosen to investigate the Langmuir isotherm adsorption equation [34]. Through Langmuir's adsorption equation, the maximum adsorption capacity $\mathrm{q}_{\mathrm{m}}$ of PF/CF aerogel composite materials was determined as PC41 (34.01 mg.g $\mathrm{g}^{-1}$ ), PC21 (33.22 mg.g ${ }^{-1}$ ), and PC11 (23.20 mg.g ${ }^{-1}$ ).
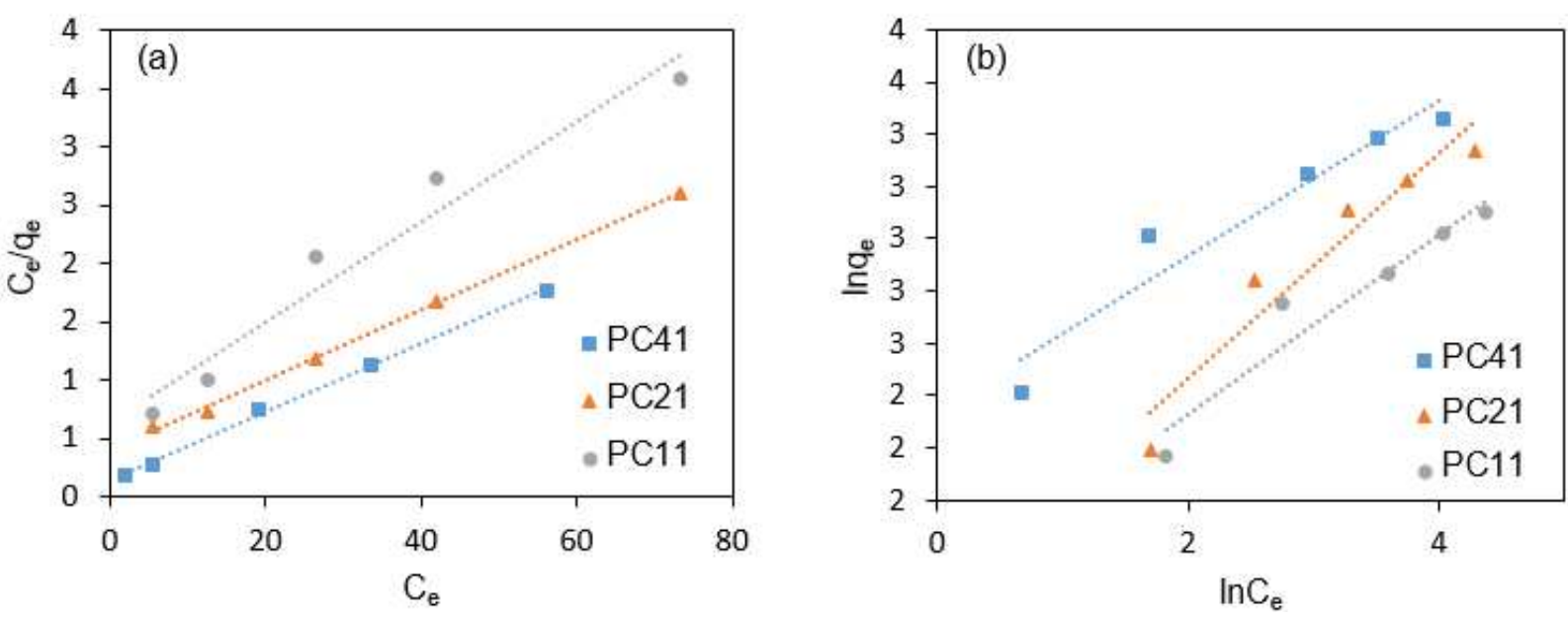

Fig. 7 Isotherms of PF/CF aerogel composite (a) Langmuir; (b) Freundlich 
Table 4. Isotherm parameters for the adsorption of MB dyes by PF/CF aerogel composite

\begin{tabular}{|c|c|c|c|c|}
\hline \multicolumn{2}{|c|}{ Samples } & PC41 & PC21 & PC11 \\
\hline \multirow{4}{*}{ Langmuir } & $\mathrm{K}_{\mathrm{L}}$ & 0.2192 & 0.0752 & 0.0677 \\
\hline & $\mathrm{R}^{2}$ & 0.9976 & 0.9985 & 0.9531 \\
\hline & $\mathrm{R}_{\mathrm{L}}$ & $0.0352-0.1543$ & $0.0961-0.3472$ & $0.1057-0.3714$ \\
\hline & $\mathrm{q}_{\mathrm{m}}$ & 34.01 & 33.22 & 23.20 \\
\hline \multirow{3}{*}{ Freundlich } & $\mathrm{K}_{\mathrm{F}}$ & 10.35 & 4.992 & 5.160 \\
\hline & $\mathrm{n}$ & 3.363 & 2.33 & 2.904 \\
\hline & $\mathrm{R}^{2}$ & 0.9291 & 0.9230 & 0.9268 \\
\hline
\end{tabular}

The adsorption of MB material compared with other studies is shown in Table 5 . The absorption capacity of the PF/CF aerogel composite on MB dyes is still quite poor, lower than that of most materials from other cellulose sources, even though the material porosity is high, but the specific surface area is low due to the gelation method. However, the fast adsorption time of PF/CF aerogel composite can be a useful candidate for quick MB cleaning applications.

Table 5. Adsorption of MB dyes by various adsorbents

\begin{tabular}{cccc}
\hline Adsorbents & Adsorption times & $\mathbf{q}_{\mathbf{m}}(\mathbf{m g} \mathbf{g})$ & References \\
\hline PF/CF aerogel composite & $20 \mathrm{~min}$ & $23.20-34.01$ & This study \\
Cellulose/Activated carbon & $50 \mathrm{~h}$ & 26.2 & {$[35]$} \\
Formaldehyde sawdust & $60-90 \mathrm{~min}$ & 51.4 & {$[36]$} \\
CMC/GO & $60 \mathrm{~min}$ & 59 & {$[37]$} \\
RCE/GO & $30 \mathrm{~min}$ & 68 & {$[25]$} \\
Activated carbon & $140 \mathrm{~min}$ & 263.69 & {$[21]$} \\
\hline
\end{tabular}

\subsubsection{Thermodynamic study}

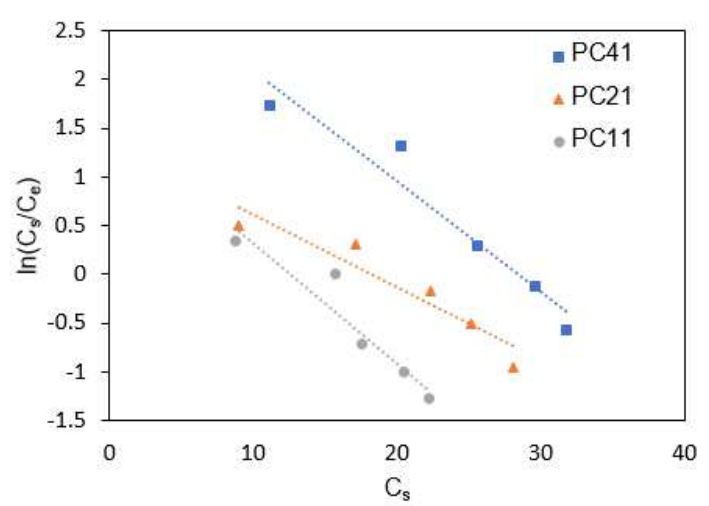

Fig. 8 Plot between $\ln \left(\mathrm{C}_{\mathrm{s}} / \mathrm{C}_{\mathrm{e}}\right)$ and $\mathrm{C}_{\mathrm{e}}$ of PF/CF aerogel composite 
From Fig. 9, $\mathrm{K}^{\circ}$ values derived from the partition coefficient can be obtained through extrapolating $\mathrm{C}_{s}$ to zero, which the Gibbs feature can be calculated. The results of Gibbs energy shown in Table 6 . The $\Delta G^{\circ}$ value below 0 indicates that $M B$ absorption is spontaneous adsorption process at the temperature condition without adding additional energy [29].

Table 6. Gibbs free energy of PF/CF aerogel composite

\begin{tabular}{ccccc}
\hline Samples & $\mathbf{R}^{2}$ & $\mathbf{K}^{\circ}$ & Temperature (K) & $\Delta \mathbf{G}^{\circ}(\mathbf{k J} / \mathbf{m o l})$ \\
\hline PC41 & 0.9373 & 3.2212 & & -2.947 \\
PC21 & 0.8882 & 1.3518 & 303 & -0.759 \\
PC11 & 0.9010 & 1.5656 & & -1.113 \\
\hline
\end{tabular}

\section{Conclusion}

The PF/CF aerogel composite with outstanding mechanical strength has been successfully synthesized from pineapple leaf fibers and cotton waste fibers by using the sol-gel method with sodium hydroxide $\mathrm{NaOH} /$ urea solution as a solvent and followed by freeze-drying. The fabricated aerogel composite exhibits low density and high porosity, and robust compressive modulus of $0.053-0.069 \mathrm{~g} . \mathrm{cm}^{-3}, 94.7$ to $95.2 \%$, and $110.25-182.93 \mathrm{kPa}$, respectively. The motor oil adsorption of PF/CF aerogel composites occurs effectively, with adsorption capacity nearly 16 times their weight. Whereas, the maximum MB adsorption capacity of $34.01 \mathrm{mg} \cdot \mathrm{g}^{-1}$ is determined for PF/CF aerogel composite having the highest cotton fiber content. This proves that PF/CF aerogel composite fabricated in this study could be a promising material to be used to deal with the removal of organic pollutants in contaminated water treatment.

\section{Acknowledgements}

This work was funded by Vingroup Joint Stock Company and supported by Vingroup Innovation Foundation (VINIF) under project code VINIF.2020.NCUD.DA112. We acknowledge the support of time and facilities from Ho Chi Minh City University of Technology (HCMUT), VNU-HCM for this study.

\section{Declarations of interest}

The authors declare no potential conflicts of interest concerning the research, authorship, and/or publication of this article. 


\section{Credit authorship contribution statement}

Phu V. Vu: Visualization, Writing - original draft; Trung D. Doan: Investigation, Data analysis; Giang C. Tu: Methodology, Characterization; Nga H.N. Do: Conceptualization, Supervision, Writing - review \& editing; Kien A. Le: Resources, Writing - review \& editing; Phung K. Le: Validation, Project administration, Funding acquisition.

\section{Nomenclature}

$\varphi$

Porosity

$\rho_{a} \quad$ Bulk density

$\rho_{b} \quad$ The average true density of components

$C_{P F} \quad$ The mass concentration PF

$C_{C F} \quad$ The mass concentration $\mathrm{CF}$

$C_{0} \quad$ Initial concentrations of adsorbate

$C_{t} \quad$ Concentrations of adsorbate at various time $t$

$V \quad$ Solution's volume

$m \quad$ Mass of component

$q_{t} \quad$ Adsorption capacity at various time $t$

$k_{1} \quad$ The kinetic rate constant of the pseudo-first order model of adsorption

$k_{2} \quad$ The kinetic rate constant of the pseudo-second order model of adsorption

$K_{L} \quad$ The Langmuir constant

$q_{e} \quad$ The equilibrium adsorption capacity

$q_{m} \quad$ The maximum adsorption capacity

$R_{L} \quad$ Equilibrium parameter

$K_{F} \quad$ The Freundlich constant

$n \quad$ The empirical constant

$C_{e} \quad$ The equilibrium adsorbate concentration

$K^{\circ} \quad$ Thermodynamic distribution coefficient

$\gamma_{s} \quad$ The activity coefficient of adsorbed ions

$\gamma_{e} \quad$ The activity coefficient at equilibrium

$C_{s} \quad$ The concentration of adsorbate on the adsorbent 


$\begin{array}{ll}\Delta G^{\circ} & \text { The Gibbs free energy } \\ \mathrm{R} & \text { The ideal gas constant } \\ \mathrm{T} & \text { Absolute temperature } \\ \mathrm{CMC} & \text { Carboxymethyl cellulose } \\ \mathrm{GO} & \text { Graphite oxide } \\ \mathrm{RCE} & \text { Regenerated cellulose }\end{array}$

\section{References}

[1] B. Li, L. Wu, L. Li, S. Seeger, J. Zhang, A. Wang, Superwetting double-layer polyester materials for effective removal of both insoluble oils and soluble dyes in water, ACS Appl. Mater. Interfaces. 6 (2014) 11581-11588. https://doi.org/10.1021/am502313h.

[2] J. Xiao, J. Zhang, W. Lv, Y. Song, Q. Zheng, Multifunctional graphene/poly(vinyl alcohol) aerogels: In situ hydrothermal preparation and applications in broadspectrum adsorption for dyes and oils, Carbon N. Y. 123 (2017) 354-363. https://doi.org/10.1016/j.carbon.2017.07.049.

[3] J. Wang, T. Tsuzuki, B. Tang, L. Sun, X.J. Dai, G.D. Rajmohan, J. Li, X. Wang, Recyclable textiles functionalized with reduced graphene Oxide@ZnO for removal of oil spills and dye pollutants, Aust. J. Chem. 67 (2014) 71-77. https://doi.org/10.1071/CH13323.

[4] Q.B. Thai, D.K. Le, N.H.N. Do, P.K. Le, N. Phan-Thien, C.Y. Wee, H.M. Duong, Advanced aerogels from waste tire fibers for oil spill-cleaning applications, J. Environ. Chem. Eng. 8 (2020) 104016. https://doi.org/10.1016/j.jece.2020.104016.

[5] T. Zhang, Z. Li, Y. Lü, Y. Liu, D. Yang, Q. Li, F. Qiu, Recent progress and future prospects of oil-absorbing materials, Chinese J. Chem. Eng. 27 (2019) 1282-1295. https://doi.org/10.1016/j.cjche.2018.09.001.

[6] Q.B. Thai, S.T. Nguyen, D.K. Ho, T. Du Tran, D.M. Huynh, N.H.N. Do, T.P. Luu, P.K. Le, D.K. Le, N. Phan-Thien, H.M. Duong, Cellulose-based aerogels from sugarcane bagasse for oil spill-cleaning and heat insulation applications, Carbohydr. Polym. 228 (2020) 115365. https://doi.org/10.1016/j.carbpol.2019.115365.

[7] S.M. El-Kousy, H.G. El-Shorbagy, M.A.A. El-Ghaffar, Chitosan/montmorillonite composites for fast removal of methylene blue from aqueous solutions, Mater. Chem. Phys. 254 (2020). https://doi.org/10.1016/j.matchemphys.2020.123236.

[8] W. Wan, R. Zhang, W. Li, H. Liu, Y. Lin, L. Li, Y. Zhou, Graphene-carbon nanotube aerogel as an ultra-light, compressible and recyclable highly efficient absorbent for oil and dyes, Environ. Sci. Nano. 3 (2016) 107-113. 
https://doi.org/10.1039/C5EN00125K

[9] F. Jiang, D.M. Dinh, Y.-L. Hsieh, Adsorption and desorption of cationic malachite green dye on cellulose nanofibril aerogels, Carbohydr. Polym. 173 (2017) 286-294. https://doi.org/10.1016/j.carbpol.2017.05.097.

[10] J. Liu, T.-W. Chen, Y.-L. Yang, Z.-C. Bai, L.-R. Xia, M. Wang, X.-L. Lv, L. Li, Removal of heavy metal ions and anionic dyes from aqueous solutions using amidefunctionalized cellulose-based adsorbents, Carbohydr. Polym. 230 (2020) 115619. https://doi.org/https://doi.org/10.1016/j.carbpol.2019.115619.

[11] A. DeVierno Kreuder, T. House-Knight, J. Whitford, E. Ponnusamy, P. Miller, N. Jesse, R. Rodenborn, S. Sayag, M. Gebel, I. Aped, A method for assessing greener alternatives between chemical products following the 12 principles of green chemistry, ACS Sustain. Chem. Eng. 5 (2017) 2927-2935. https://doi.org/10.1021/acssuschemeng.6b02399

[12] N.H.N. Do, T.P. Luu, Q.B. Thai, D.K. Le, N.D.Q. Chau, S.T. Nguyen, P.K. Le, N. PhanThien, H.M. Duong, Advanced fabrication and application of pineapple aerogels from agricultural waste, Mater. Technol. 35 (2020) 807-814. https://doi.org/10.1080/10667857.2019.1688537.

[13] N.H.N. Do, T.P. Luu, Q.B. Thai, D.K. Le, N.D.Q. Chau, S.T. Nguyen, P.K. Le, N. PhanThien, H.M. Duong, Heat and sound insulation applications of pineapple aerogels from pineapple waste, Mater. Chem. Phys. 242 (2020). https://doi.org/10.1016/j.matchemphys.2019.122267.

[14] L. Zuo, Y. Zhang, L. Zhang, Y.-E. Miao, W. Fan, T. Liu, Polymer/carbon-based hybrid aerogels: preparation, properties and applications, Materials (Basel). 8 (2015) 68066848. https://doi.org/10.3390/ma8105343

[15] N.H.N. Do, V.T. Tran, B.M. Tran, K.A. Le, Q.B. Thai, P.T.T. Nguyen, H.M. Duong, P.K. Le, Recycling of Pineapple Leaf and Cotton Waste Fibers into Heat-insulating and Flexible Cellulose Aerogel Composites, (n.d.). https://doi.org/10.1007/s10924-02001955-w.

[16] H. Cheng, B. Gu, M.P. Pennefather, T.X. Nguyen, N. Phan-Thien, H.M. Duong, Cotton aerogels and cotton-cellulose aerogels from environmental waste for oil spillage $\begin{array}{lllll}\text { cleanup, } & \text { Mater. } & \text { Des. } & 130 & \text { (2017) 452-458. }\end{array}$ https://doi.org/10.1016/j.matdes.2017.05.082.

[17] J. Wang, S. Liu, Remodeling of raw cotton fiber into flexible, squeezing-resistant macroporous cellulose aerogel with high oil retention capability for oil/water $\begin{array}{lllll}\text { separation, Sep. Purif. Technol. } 221 & \text { (2019) 303-310. }\end{array}$ 
https://doi.org/10.1016/j.seppur.2019.03.097.

[18] Z.E. Lim, Q.B. Thai, D.K. Le, T.P. Luu, P.T.T. Nguyen, N.H.N. Do, P.K. Le, N. PhanThien, X.Y. Goh, H.M. Duong, Functionalized pineapple aerogels for ethylene gas adsorption and nickel (II) ion removal applications, J. Environ. Chem. Eng. 8 (2020) 104524. https://doi.org/10.1016/j.jece.2020.104524.

[19] T. Budtova, P. Navard, Cellulose in $\mathrm{NaOH}-$ water based solvents: a review, Cellulose. 23 (2016) 5-55. https://doi.org/10.1007/s10570-015-0779-8.

[20] M. Fauziyah, W. Widiyastuti, R. Balgis, H. Setyawan, Production of cellulose aerogels from coir fibers via an alkali-urea method for sorption applications, Cellulose. 26 (2019) 9583-9598. https://doi.org/10.1007/s10570-019-02753-x.

[21] Y. Li, Q. Du, T. Liu, X. Peng, J. Wang, J. Sun, Y. Wang, S. Wu, Z. Wang, Y. Xia, L. Xia, Comparative study of methylene blue dye adsorption onto activated carbon, graphene oxide, and carbon nanotubes, Chem. Eng. Res. Des. 91 (2013) 361-368. https://doi.org/10.1016/j.cherd.2012.07.007.

[22] P. Jia, H. Tan, K. Liu, W. Gao, Removal of methylene blue from aqueous solution by bone char, Appl. Sci. 8 (2018) 1903. https://doi.org/10.3390/app8101903

[23] M. Mahardika, H. Abral, A. Kasim, S. Arief, M. Asrofi, Production of nanocellulose from pineapple leaf fibers via high-shear homogenization and ultrasonication, Fibers. 6 (2018) 1-12. https://doi.org/10.3390/fib6020028.

[24] J.E. Castle, P.A. Zhdan, Characterization of surface topography by SEM and SFM: problems and solutions, J. Phys. D. Appl. Phys. 30 (1997) 722. https://doi.org/10.1088/0022-3727/30/5/004

[25] F. Ren, Z. Li, W.Z. Tan, X.H. Liu, Z.F. Sun, P.G. Ren, D.X. Yan, Facile preparation of $3 \mathrm{D}$ regenerated cellulose/graphene oxide composite aerogel with high-efficiency adsorption towards methylene blue, J. Colloid Interface Sci. 532 (2018) 58-67. https://doi.org/10.1016/j.jcis.2018.07.101.

[26] J.H. Beh, T.H. Lim, J.H. Lew, J.C. Lai, Cellulose nanofibril-based aerogel derived from sago pith waste and its application on methylene blue removal, Int. J. Biol. Macromol. 160 (2020) 836-845. https://doi.org/10.1016/j.ijbiomac.2020.05.227.

[27] M.D. LeVan, T. Vermeulen, Binary Langmuir and Freundlich isotherms for ideal adsorbed solutions, J. Phys. Chem. 85 (1981) 3247-3250. https://doi.org/10.1021/j150622a009.

[28] Z. Ezzeddine, I. Batonneau-Gener, Y. Pouilloux, H. Hamad, Removal of methylene blue by mesoporous CMK-3: Kinetics, isotherms and thermodynamics, J. Mol. Liq. 223 (2016) 763-770. https://doi.org/10.1016/j.molliq.2016.09.003. 
[29] H.N. Tran, S.J. You, A. Hosseini-Bandegharaei, H.P. Chao, Mistakes and inconsistencies regarding adsorption of contaminants from aqueous solutions: A critical review, Water Res. 120 (2017) 88-116. https://doi.org/10.1016/j.watres.2017.04.014.

[30] S. Zhang, W.C. Wang, F.X. Li, J.Y. Yu, Swelling and dissolution of cellulose in $\mathrm{NaOH}$ aqueous solvent systems, Cellul. Chem. Technol. 47 (2013) 671-679. https://doi.org/10.1007/s10570-015-0809-6.

[31] M. Fauziyah, W. Widiyastuti, H. Setyawan, A hydrophobic cellulose aerogel from coir fibers waste for oil spill application, IOP Conf. Ser. Mater. Sci. Eng. 778 (2020). https://doi.org/10.1088/1757-899X/778/1/012019.

[32] X. Chang, D. Chen, X. Jiap, Chitosan-based aerogels with high adsorption performance, J. Phys. Chem. B. 112 (2008) 7721-7725. https://doi.org/10.1021/jp8011359.

[33] T. Ahmad, M. Danish, M. Rafatullah, A. Ghazali, O. Sulaiman, R. Hashim, M.N.M. Ibrahim, The use of date palm as a potential adsorbent for wastewater treatment: A review, Environ. Sci. Pollut. Res. 19 (2012) 1464-1484. https://doi.org/10.1007/s11356-011-0709-8.

[34] T.M. Budnyak, S. Aminzadeh, I. V. Pylypchuk, D. Sternik, V.A. Tertykh, M.E. Lindström, O. Sevastyanova, Methylene Blue dye sorption by hybrid materials from technical lignins, J. Environ. Chem. Eng. 6 (2018) 4997-5007. https://doi.org/10.1016/j.jece.2018.07.041.

[35] Q. Bai, Q. Xiong, C. Li, Y. Shen, H. Uyama, Hierarchical porous cellulose/activated carbon composite monolith for efficient adsorption of dyes, Cellulose. 24 (2017) 42754289. https://doi.org/10.1007/s10570-017-1410-y.

[36] V.K. Garg, R. Gupta, A.B. Yadav, R. Kumar, Dye removal from aqueous solution by adsorption on treated sawdust, Bioresour. Technol. 89 (2003) 121-124. https://doi.org/10.1016/S0960-8524(03)00058-0.

[37] J. Liu, H. Chu, H. Wei, H. Zhu, G. Wang, J. Zhu, J. He, Facile fabrication of carboxymethyl cellulose sodium/graphene oxide hydrogel microparticles for water purification, RSC Adv. 6 (2016) 50061-50069. https://doi.org/10.1039/c6ra06438h. 


\section{Highlights}

- Pineapple leaf and cotton waste fibers are combined for synthesis aerogel composite using alkali-urea for the first time.

- PF/CF aerogel composites show remarkable high compressive modulus (90.97- 203.72 $\mathrm{kPa})$.

- PF/CF aerogel composites exhibit great adsorption ability for oil adsorption.

- The adsorption of PF/CF aerogel composites on MB dyes exhibit a short removal time. 


\section{Graphical abstract}

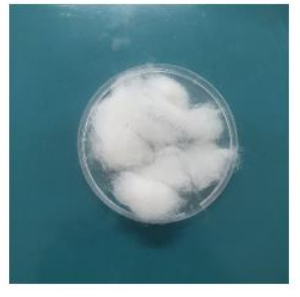

Cotton fiber

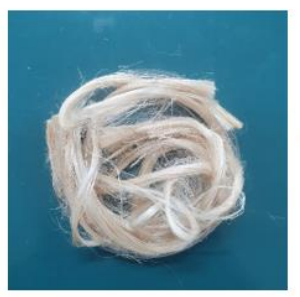

Pineapple leaf fiber
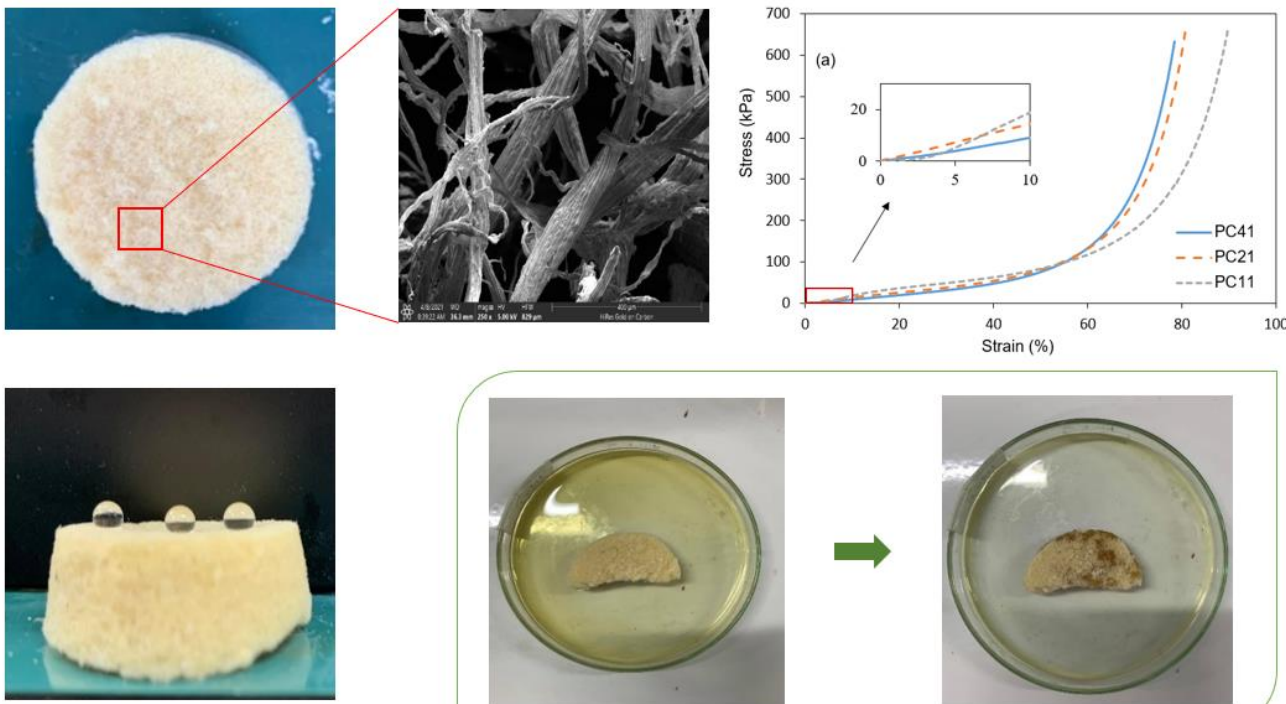

PF/CF aerogel composite

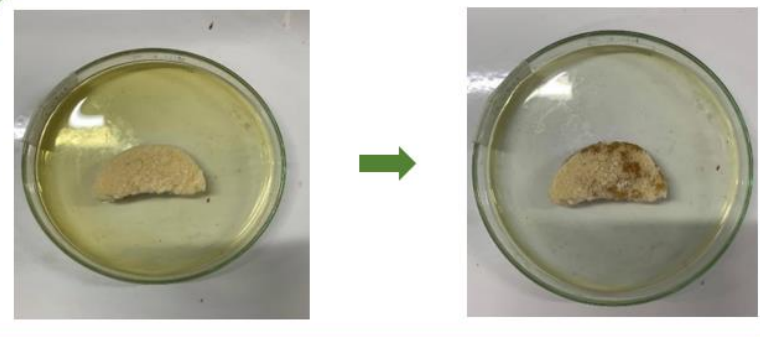

Oil adsorption 